\title{
Pyrolysis of Plastics to Liquid Fuel Using Sulphated Zirconium Hydroxide Catalyst
}

\author{
Achyut K. Panda ${ }^{1} \cdot$ Abdullah Alotaibi $^{2,3} \cdot$ Ivan V. Kozhevnikov ${ }^{2}$ (D) N. Raveendran Shiju ${ }^{4}$ (D)
}

Received: 13 October 2018 / Accepted: 3 October 2019 / Published online: 18 October 2019

(c) The Author(s) 2019

\begin{abstract}
A world without plastics is unimaginable now and probably also in future. With the growing use of plastic, the problem of waste plastic disposal is also growing. Recycling the plastics is a promising option to avoid the serious environmental challenge caused by them. Among the various options for recycling, catalytic conversion of plastics to hydrocarbons is very attractive. Catalytic pyrolysis depolymerizes the plastics to an oil which can be used as a liquid fuel. This is a sustainable way to utilize the waste, simultaneously promising to meet the energy demand. We studied the use of sulphated zirconium hydroxide as a catalyst for the pyrolysis of different types of plastics such as polypropylene, low density polyethylene, high density polyethylene and a mixture of all three. The objective was to understand the effect of the catalyst and the temperature on the composition of the oil as well as to find an optimum condition for maximum oil yield. Various reaction conditions and their influence on the product distribution are studied. The catalyst is effective in enhancing the reaction rate, altering the product selectivity and narrowing the product distribution of the reaction. At optimum conditions, we obtained more than $79 \%$ yield of oil which contains mainly $\mathrm{C}_{10}-\mathrm{C}_{24}$ hydrocarbons. The fuel properties are suitable to be used as a fossil fuel substitute.
\end{abstract}

Graphic Abstract

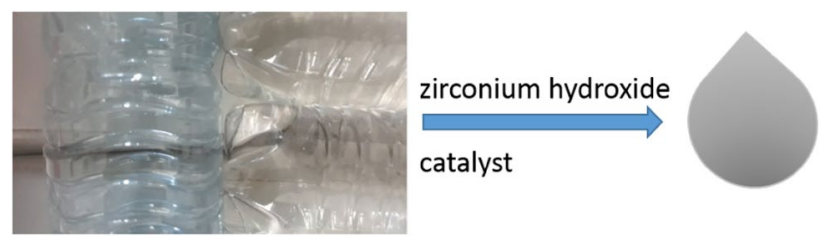

Keywords Catalyst $\cdot$ Zirconium hydroxide $\cdot$ Plastics $\cdot$ Fuels $\cdot$ Pyrolysis

Electronic supplementary material The online version of this article (doi:https://doi.org/10.1007/s12649-019-00841-4) contains supplementary material, which is available to authorized users.

Achyut K. Panda

akpanda_chem@vssut.ac.in

$\triangle$ N. Raveendran Shiju

n.r.shiju@uva.nl

1 Department of Chemistry, Veer Surendra Sai University of Technology, Burla, Odisha 768018, India

2 Department of Chemistry, School of Physical Sciences, University of Liverpool, Liverpool L69 7ZD, UK
3 Department of Chemistry, College of Science and Humanities At Ad-Dawadmi, Shaqra University, P.O. Box 1040, Ad-Dawadmi 11911, Saudi Arabia

4 Van't Hoff Institute for Molecular Sciences, University of Amsterdam, P.O. Box 94157, 1090 GD Amsterdam, The Netherlands 


\section{Statement of Novelty}

Pyrolysis of plastics using sulphated zirconium hydroxide catalyst yields $>79 \%$ oil, containing $\mathrm{C}_{10}-\mathrm{C}_{24}$ hydrocarbons, suitable for use as fuel. Such a detailed study with sulphated zirconium hydroxide catalyst is new.

\section{Introduction}

Plastic products have become an integral part in our daily life. 8.3 billion metric tons of plastics have been produced till 2017 since the beginning of the large scale production [1]. 79\% of this is disposed of in landfills, where its resources are wasted and the material takes up valuable space [1]. According to a recent report of the World Watch Institute, an average person living in Western Europe or North America consumes $100 \mathrm{~kg}$ of plastic each year [2]. Asia uses $20 \mathrm{~kg}$ per person, but this figure is expected to grow rapidly because of the fast economic growth. In India alone, the demand for plastic products is set to grow at a rate of $16 \%[3,4]$.

The discarded plastics after their use (plastic waste) never degrade and remain on landscape for several years. The plastic waste is recyclable; however it is not a permanent solution. The recycling of a virgin plastic material can be done $2-3$ times only because after every recycling, the plastic material deteriorates due to thermal pressure resulting in a reduced lifespan. Approximately $70 \%$ of plastic packaging products are converted into plastic waste in a short span. A few technologies have been developed to minimize the adverse effect of plastics on the environment. The most common technology currently used for the plastic disposal is incineration. However, it is not the best option because it releases toxic gases like chlorinated dioxins and furans, raising several environmental issues. Other innovative technical options are the utilization of plastic waste in road construction, co-processing of plastic waste as alternative fuel and raw material in cement kilns and power plants, conversion of plastic waste into liquid oil, plasma pyrolysis, extrusion and palletization $[5,6]$.

Among the above mentioned technologies, conversion of waste plastics to fuel, especially catalytic, is preferred as it provides a plausible solution to solid waste management and subsequently generates alternative energy that would balance the depletion of fossil fuels. There are many reports of extensive research and commercialization of the waste plastic to fuel process. Different parameters such as temperature, feed composition or plastic type, particle size, catalyst loading, catalyst to plastic ratios, reactor type, polymer-catalyst contact mode play very important role in design of a plastic pyrolysis process for the efficient production of gasoline and diesel grade fuel $[5,6]$.

The pyrolysis of plastics is endothermic and high energy consuming process. It requires at least $350-500{ }^{\circ} \mathrm{C}$ and temperatures as high as $700-900{ }^{\circ} \mathrm{C}$ may be needed for achieving better product yields. Product distribution and yield of a definite fraction are significantly affected by temperature [5]. Several types of reactors such as fixed bed, fluidised bed, conical spouted bed, transported bed reactors, stirred tank reactors and kiln-type reactors are used for pyrolysis. The type of the reactor can influence the decomposition behaviour of the feedstock, process as well as economic efficiency of the process [5, 7]. Polyolefins such as HDPE, LDPE and PP are the most ideal waste plastic type for the production of diesel and gasoline range fuel. Presence of small amount of PS are desirable and allowed to provide aromatic components to the fuel $[5,7]$. Thermal degradation of plastics in the absence of a catalyst often results in wide product distributions and thus requires further treatment to obtain valuable products. Catalyst plays an important role in improving the product distribution, quality and quantity of gaseous and liquid products $[5,8,9]$. A large number of research efforts on the catalytic pyrolysis of plastics in different conditions using different catalysts are reported. The most important features that a catalyst should possess for pyrolysis of plastic include surface area, pore structure and acidity. The cracking of the oligomers becomes favorable when the catalyst has a high mesoporous surface area. The majority of the catalysts reported for plastic pyrolysis are acidic because the defective sites in polymers can be protonated to form on-chain carbocations. The acidity influences the quality of the fuel and the distribution of various fractions obtained by pyrolysis.

The different categories of the catalysts used for the plastic pyrolysis include zeolites, mesoporous materials, carbon and clay. Different zeolite catalysts used recently for this process include conventional microporous zeolites (HZSM-5, HBeta, HY,etc.), zeolitic nano-catalysts (n-ZSM5, n-MOR, n-USY), Lamellar and pillared ZSM-5 zeolites as well as hierarchical zeolites [7-15]. Also, functionalised silica, silico-alumino-phosphates, FCC catalysts and gallosilicates are used for plastic waste valorisation. The mesoporous materials used in the reaction include MCM-41, FSM-16, Al-UTD-1, Al-MCM-41, Al-SBA-15 and KFS-16. Thermal cracking often produces hydrocarbons with wide range of carbon numbers, whereas with catalytic cracking, narrow product distribution can be obtained. The product distribution again depends on the pore size of the catalysts, that is, micro or mesoporous [11-15]. Activated carbon is also widely used by different researchers for plastic pyrolysis. Metals (platinum, iron, molybdenum, zinc, cobalt, nickel, and copper) supported over activated carbon are reported to increase the activity as compared to the metal-free catalyst. Different types of clay such as kaolinite, calcium bentonite, 
montmorillonite, saponite, albite, pyrophyllite, halloysite, restructured smectite clays, acid modified clay, as well as their Al- and Fe/Al-pillared derivatives were also tried as catalysts in this process. Basic oxides $\left(\mathrm{BaO}, \mathrm{K}_{2} \mathrm{O}\right)$, magnesium carbonate, barium carbonate, calcium carbonate were also used as catalysts in the degradation of different plastics [7-15].

However, more studies are still required to develop a catalyst that is very efficient, cheap and stable for designing commercial scale pyrolysis processes. In this context, here we report the pyrolysis of plastics to liquid fuels by a sulphated zirconium hydroxide catalyst. The catalyst can be easily synthesized on a larger scale and not expensive for commercial use. It is very active and converts various types of plastics to fuels efficiently.

\section{Experimental Section}

Pellets ( $2.5 \mathrm{~mm}$ in size) of three different types of plastics, polypropylene (density $0.905 \mathrm{~g} / \mathrm{cc}$ and melt flow index (MFI) values $8-9 \mathrm{~g} / 10 \mathrm{~min}$ at $230{ }^{\circ} \mathrm{C}$ and $2.16 \mathrm{~kg}$ load), low density polyethylene (density $0.917 \mathrm{~g} / \mathrm{cc}$ and MFI $7 \mathrm{~g} / 10 \mathrm{~min}$ at $230{ }^{\circ} \mathrm{C}$ and $2.16 \mathrm{~kg}$ load), and high density polyethylene (density $0.954 \mathrm{~g} / \mathrm{cc}$ and MFI $1.20 \mathrm{~g} / 10 \mathrm{~min}$ at $230{ }^{\circ} \mathrm{C}$ and $2.16 \mathrm{~kg}$ load) procured from Reliance Industries Limited, India were used for the experiments.

We used sulphated zirconium hydroxide as the catalyst. The catalyst was prepared by sulphating an amorphous zirconium hydroxide precursor with ammonium sulfate. Zirconium hydroxide was prepared by the controlled addition of aqueous zirconium oxychloride $\left(\mathrm{ZrOCl}_{2} \cdot 8 \mathrm{H}_{2} \mathrm{O}\right.$, SigmaAldrich) solution to an $\mathrm{NH}_{4} \mathrm{OH}(2 \mathrm{M}) / \mathrm{NH}_{4} \mathrm{Cl}(2 \mathrm{M})$ buffer solution to keep the $\mathrm{pH}$ at a constant value of 10.5 [16-18]. The solid was filtered and thoroughly washed with distilled water to remove the chlorides. $\mathrm{Zr}$ hydroxide was then suspended in an aqueous solution of $1 \mathrm{~N}$ ammonium sulfate ( $20 \mathrm{ml}$ solution $/ \mathrm{g}$ of $\mathrm{Zr}$ hydroxide sample). The mixture was stirred for $2 \mathrm{~h}$, slowly evaporated to dryness, and finally calcined in dry air at $450{ }^{\circ} \mathrm{C}$ for $3 \mathrm{~h}$ before use.

We characterized the catalyst by X-ray diffraction, surface area and DRIFT spectroscopy. The surface area of the sample was $210 \mathrm{~m}^{2} / \mathrm{g}$ and sulfate content was around 2 groups per $\mathrm{nm}^{2}$. The number of sulfate groups was calculated based on the amount of sulfate and the surface area of the sample. Powder X-ray diffractograms were recorded at ambient temperature using a Rigaku Mini Flex II diffractometer with $\mathrm{Ni}$ filtered $\mathrm{CuK} \alpha$ radiation $(\lambda=1.5406$ $\AA$ ). DRIFT (diffuse reflectance infrared Fourier transform) spectrum of adsorbed pyridine was recorded on a Nicolet Nexus FTIR spectrometer using powdered 1:4 w/w catalyst mixture with $\mathrm{KBr}$. The catalyst- $\mathrm{KBr}$ mixture was pre-treated at $150{ }^{\circ} \mathrm{C} / 3 \times 10^{-3} \mathrm{~mm} \mathrm{Hg}$ for $2 \mathrm{~h}$, then exposed to pyridine vapor at room temperature for $1 \mathrm{~h}$, followed by pumping out at $150{ }^{\circ} \mathrm{C} / 3 \times 10^{-3} \mathrm{~mm} \mathrm{Hg}$ for $1 \mathrm{~h}$ to remove physisorbed pyridine. The DRIFT spectrum of adsorbed pyridine was recorded at room temperature at a $4 \mathrm{~cm}^{-1}$ resolution against $1: 4 \mathrm{w} / \mathrm{w}$ catalyst- $\mathrm{KBr}$ mixture heated at $150{ }^{\circ} \mathrm{C}$ for $2 \mathrm{~h}$ at $3 \times 10^{-3} \mathrm{~mm} \mathrm{Hg}$ pressure.

Thermogravimetric analyses of the samples were carried out with a Shimadzu DTG-60/60H instrument. A known weight of the sample was heated in a silica crucible at a constant heating rate of $10^{\circ} \mathrm{C} / \mathrm{min}$ operating in static air atmosphere from 35 to $600{ }^{\circ} \mathrm{C}$. This is followed by cooling the system by passing a stream of air with a flow rate of $40 \mathrm{ml} / \mathrm{min}$.

FTIR spectra of the pyrolysis oil obtained at different temperatures were taken in a Perkin-Elmer Fourier transform infrared spectrophotometer with resolution of $4 \mathrm{~cm}^{-1}$, in the range of $400-4000 \mathrm{~cm}^{-1}$ using Nujol mull as reference to know the functional group composition.

The components of liquid product were analysed using GC-MS-QP 2010 (Shimadzu). A capillary tube $(\mathrm{L}=30 \mathrm{~m}$ and $\mathrm{D}=0.25 \mathrm{~mm}$ ) coated with a $0.25 \mu \mathrm{m}$ film of DB-5 and split mode injection (split ratio: 10) was used. Helium gas (99.99\% purity) was used as carrier gas at flow rate of $1.50 \mathrm{ml} / \mathrm{min}$. The oven initial temperature was set to $70{ }^{\circ} \mathrm{C}$ for $2 \mathrm{~min}$ and then increased to $300{ }^{\circ} \mathrm{C}$ at a rate of $10^{\circ} \mathrm{C} / \mathrm{min}$ and maintained for 7-8 min. The MS is maintained with ion source temperature is $200{ }^{\circ} \mathrm{C}$, interface temperature with $\mathrm{m} / \mathrm{z} 40-1000$.

The pyrolysis setup used in this experiment consists of a reactor made of stainless steel tube (length $145 \mathrm{~mm}$, internal diameter $37 \mathrm{~mm}$ and outer diameter $41 \mathrm{~mm}$ ) sealed at one end and an outlet tube at other end. The SS tube is heated externally by an electric furnace, with the temperature being measured by a $\mathrm{Cr}-\mathrm{Al}$ : $\mathrm{K}$ type thermocouple fixed inside the reactor. The temperature was controlled by an external PID controller measured with an accuracy of $\pm 0.3 \% \mathrm{FS}\left(\mathrm{FS}=1200{ }^{\circ} \mathrm{C}\right)$ i.e. the temperature can be measured with $\pm 3.6{ }^{\circ} \mathrm{C} .20 \mathrm{~g}$ of plastic was loaded in each pyrolysis reaction under static air atmosphere. Reaction was carried out using four types of plastics samples such as PP, HDPE, LDPE and mixed plastics PP + HDPE + LDPE (in 1:1:1 by weight). Precision balance (an accuracy of 0.0001 g) of Shinko Denshi Co. Ltd, Japan (Model: DJ 300S) was used to measure the weight of the samples. In the catalytic pyrolysis, a mixture of catalyst in different concentration $(5 \%, 10 \%, 20 \%$ and $33.3 \%)$ and the plastics samples (PP, HDPE, LDPE and mixed) was subjected to pyrolysis up to the desired temperature. The reaction time was calculated from the time the reactor with the sample was inserted into the furnace chamber (at room temperature) until no more oil comes from the outlet tube. The condensable liquid products were collected through the condenser and weighed. After pyrolysis, the solid residue left out inside the reactor was weighed. Then the weight of gaseous product was calculated 
from the material balance. Reactions were carried out at different temperatures ranging from 400 to $550{ }^{\circ} \mathrm{C}$. Reproducibility of the experiments were ascertained by repeating each of the significant experiments three times.

Different properties of the pyrolysis oil such as specific gravity, viscosity, flash point, fire point, cloud point, pour point, calorific value and distillation boiling range measured by different Indian Standard methods are (Bureau of Indian standards) mentioned in Table 3 . The specific gravity is measured with an accuracy of $\pm 0.0005 \mathrm{~g} / \mathrm{ml}$ and the other parameters such as pour point, cloud point, flash point and fire point are recorded with $\pm 1^{\circ} \mathrm{C}$ accuracy.

\section{Results and Discussion}

We prepared the sulphated zirconium hydroxide catalyst by sulphating an amorphous zirconium hydroxide precursor with ammonium sulfate. The surface area of the sample was $210 \mathrm{~m}^{2} / \mathrm{g}$ and sulfate content was around 2 groups per $\mathrm{nm}^{2}$ (see the "Experimental" section for details). The XRD pattern of the catalyst showed broad peaks indicating that this is mainly amorphous (Fig. 1). The peaks starting to appear at $2 \theta \sim 30,50$ and $60^{\circ}$ correspond to the tetragonal phase of zirconia $[17,18]$.

We also did the FTIR analysis of the pyridine adsorbed on the sample, which can distinguish Brønsted and Lewis acidities. This analysis showed that the material has both Brønsted and Lewis acidities (Fig. 2). The $1445 \mathrm{~cm}^{-1}$ band is characteristic of pyridine coordinatively bound to Lewis acid sites and the band at $1545 \mathrm{~cm}^{-1}$ (corresponding to the vibration of pyridinium ions) indicates the Brønsted acid

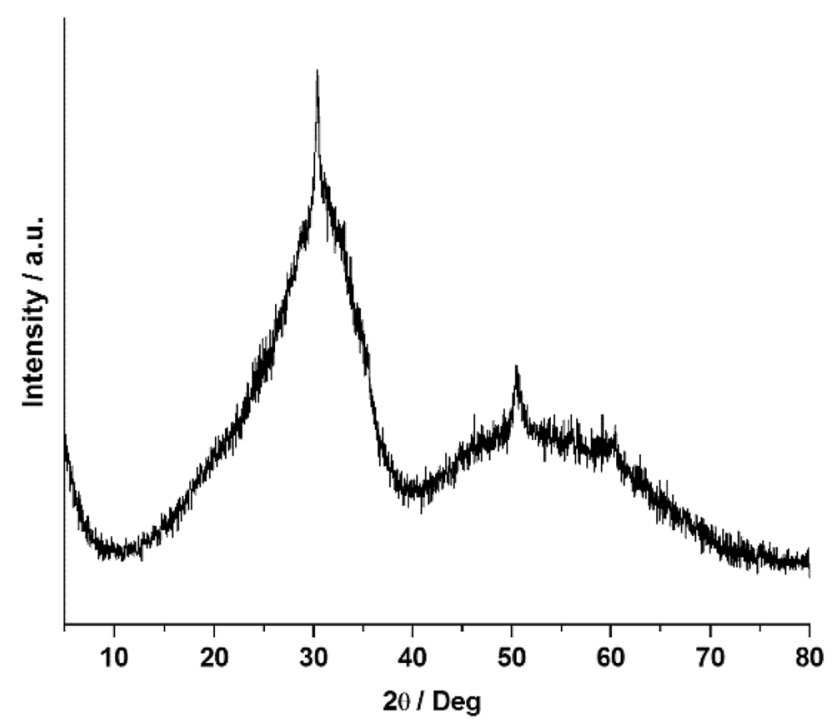

Fig. 1 XRD pattern of the calcined catalyst. The broad peaks indicate that the sample is mainly amorphous

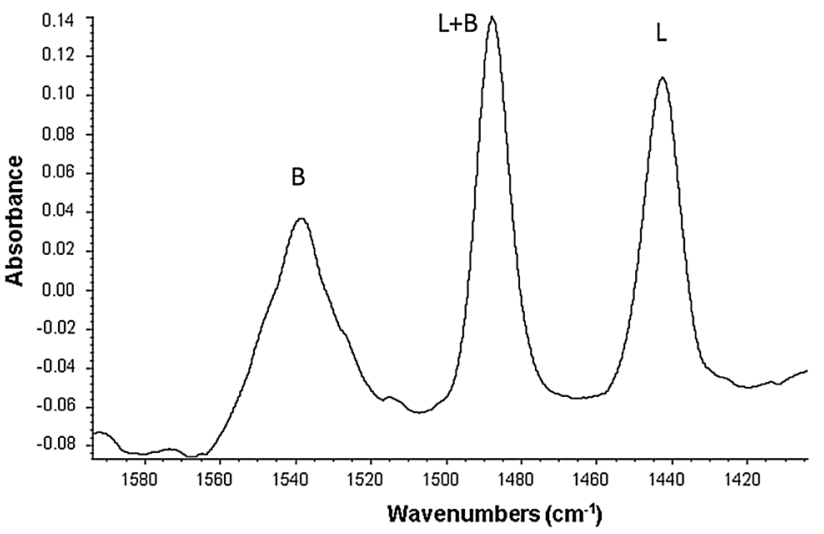

Fig. 2 FTIR of the pyridine adsorbed on the catalyst, showing peaks corresponding to both Brønsted and Lewis acidities. B and L indicate Brønsted and Lewis acidities respectively

sites. The ratio (assuming equal extinction coefficients of the corresponding bands at 1540 and $1440 \mathrm{~cm}^{-1}$ ) of Brønsted to Lewis acid site densities $(\mathrm{B} / \mathrm{L})$ is 1.18 , indicating that Brønsted acidity is slightly higher than Lewis acidity for this sample $[19,20]$.

The thermogravimetric curves (TG) for HDPE, LDPE, and PP samples are shown in Fig. 3. The TG curves of all the plastics show same weight loss step, indicating similar degradation behaviour at the given range of temperature. The degradation temperature differs for different plastics which could be attributed to macromolecular structure and pyrolysis mechanism. The temperature at which the degradation takes place is an important thermal characteristic of the plastics. In the present case, the temperature of degradation follows the following order: HDPE $>$ LDPE $>$ PP. Also, the temperatures at which weight loss of $50 \%\left(\mathrm{~T}_{50}\right)$

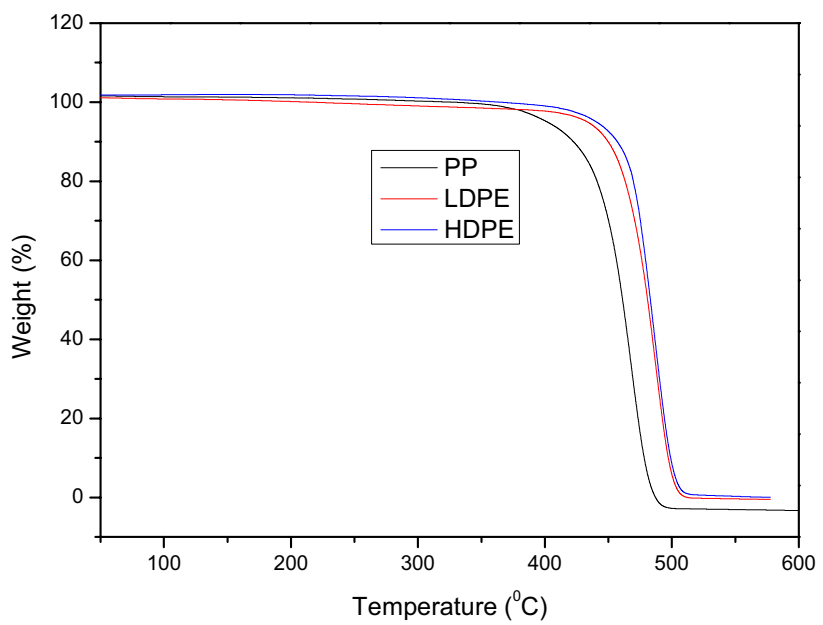

Fig. 3 TG curves of different plastics. The degradation behaviour is similar but the onset temperature of the degradation is different 
occurs are within the range of $400-500{ }^{\circ} \mathrm{C}$. Hence, we carried out the pyrolysis in the temperature range of $400-550^{\circ} \mathrm{C}$

\section{Effect of Temperature}

The pyrolysis was conducted in a steel reactor as described in the "Experimental" section using sulphated zirconium hydroxide as catalyst. The pyrolysis of HDPE, LDPE, PP and mixed plastics yielded three different products: condensed oil and/or wax, non-condensable gas, and residue. The distribution of these fractions is different at different temperatures from 400 to $550{ }^{\circ} \mathrm{C}$ [21]. The condensable oil/ wax and the non-condensable gas/volatiles fractions constituted major products as compared to the solid residue fractions. The yield distribution of different fractions was different for different plastics. The recovery of condensable fraction is very low at low temperature i.e. at $400{ }^{\circ} \mathrm{C}$ and increased with gradual increase of temperature. The condensable product obtained at low temperature $\left(400{ }^{\circ} \mathrm{C}\right.$ and $450{ }^{\circ} \mathrm{C}$ ) was low viscous liquid. Above $475^{\circ} \mathrm{C}$, the liquid became viscous/waxy. The formation of viscous and waxy product was due to improper cracking of plastic to high molecular mass hydrocarbon components. At low temperature, the reaction time was more, due to which secondary cracking of the pyrolysis product occurred inside the reactor and resulted in highly volatile product. The optimum temperature for obtaining higher yield of condensable fraction for all types of plastics and mixed plastics was $500{ }^{\circ} \mathrm{C}$. So we did further reactions at $500{ }^{\circ} \mathrm{C}$. The maximum yield of oil at the optimum condition of temperature was $82.5 \mathrm{wt} \%$ from PP, $76.6 \mathrm{wt} \%$ from LDPE, $78.9 \mathrm{wt} \%$ from HDPE and $77.2 \mathrm{wt} \%$ from mixed plastics. Coke was also formed during the reaction. The coke deposited on the catalyst can be burned out and the catalyst can be regenerated by calcining the catalyst in air at $500{ }^{\circ} \mathrm{C}$ for $4 \mathrm{~h}$.

The effect of temperature on the reaction time is shown in Fig. 4. The pyrolysis reaction rate increased and reaction time decreased with increase in temperature. High temperature easily cleaves the bonds and thus speeds up the reaction and lowers the reaction time. The reaction time for different plastics followed the trend HDPE $>$ LDPE $>$ PP at entire temperature range (see Fig. 4). This can be explained on the basis of the strength of the $\mathrm{C}-\mathrm{C}$ bond and orientation of polymer chain in different plastics. HDPE with long linear polymer chain with low branching and high degree of crystallinity has high strength and thus required more time for decomposition. Whereas LDPE with high branching and low crystallinity has weak bonds which are easily broken compared to HDPE. In PP, the presence of side chain group $\left(-\mathrm{CH}_{3}\right)$ and low crystallinity decreases the overall strength, leading to lower reaction time.

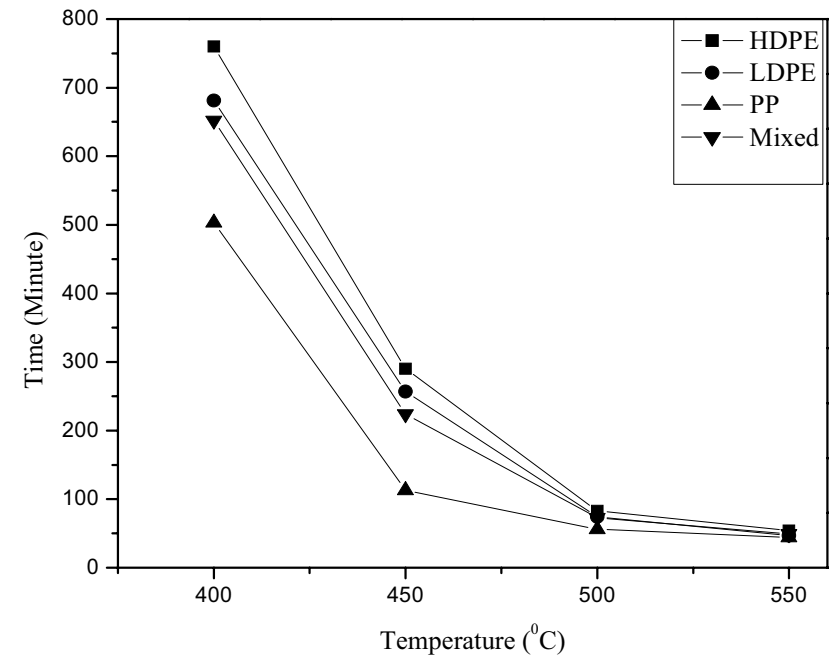

Fig. 4 Effect of temperature on the reaction time for different plastics. Heating rate is $20^{\circ} \mathrm{C} / \mathrm{min}$

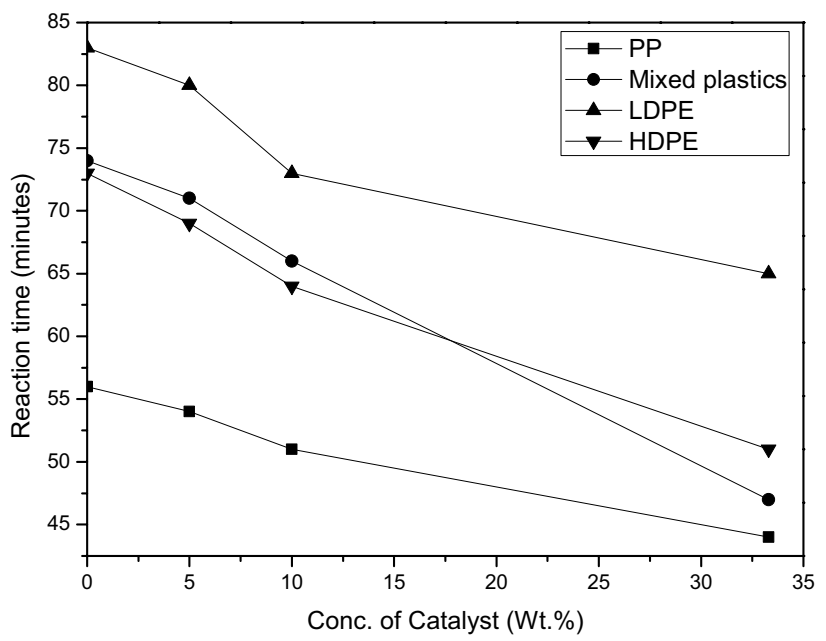

Fig. 5 Effect of catalyst concentration on the reaction time for different plastics. A mixture of catalyst in different concentration $(5 \%$, $10 \%$, and 33.3\%) and the plastic samples (PP, HDPE, LDPE and mixed) was subjected to pyrolysis at $500{ }^{\circ} \mathrm{C}$

\section{Effect of Catalyst}

The addition of sulphated zirconium hydroxide catalyst affected the rate of reaction, product distribution as well as the quality of the condensable fraction. The reaction time for catalytic pyrolysis of different plastics decreased with increase in catalyst concentration (Fig. 5).

This increase in the rate of reaction is due to the high surface area and strong acidity of the catalyst. Percentage of gaseous products increased in presence of catalyst and it was further increased with increase in concentration of catalyst (Fig. 6). The optimum catalyst concentration for the 

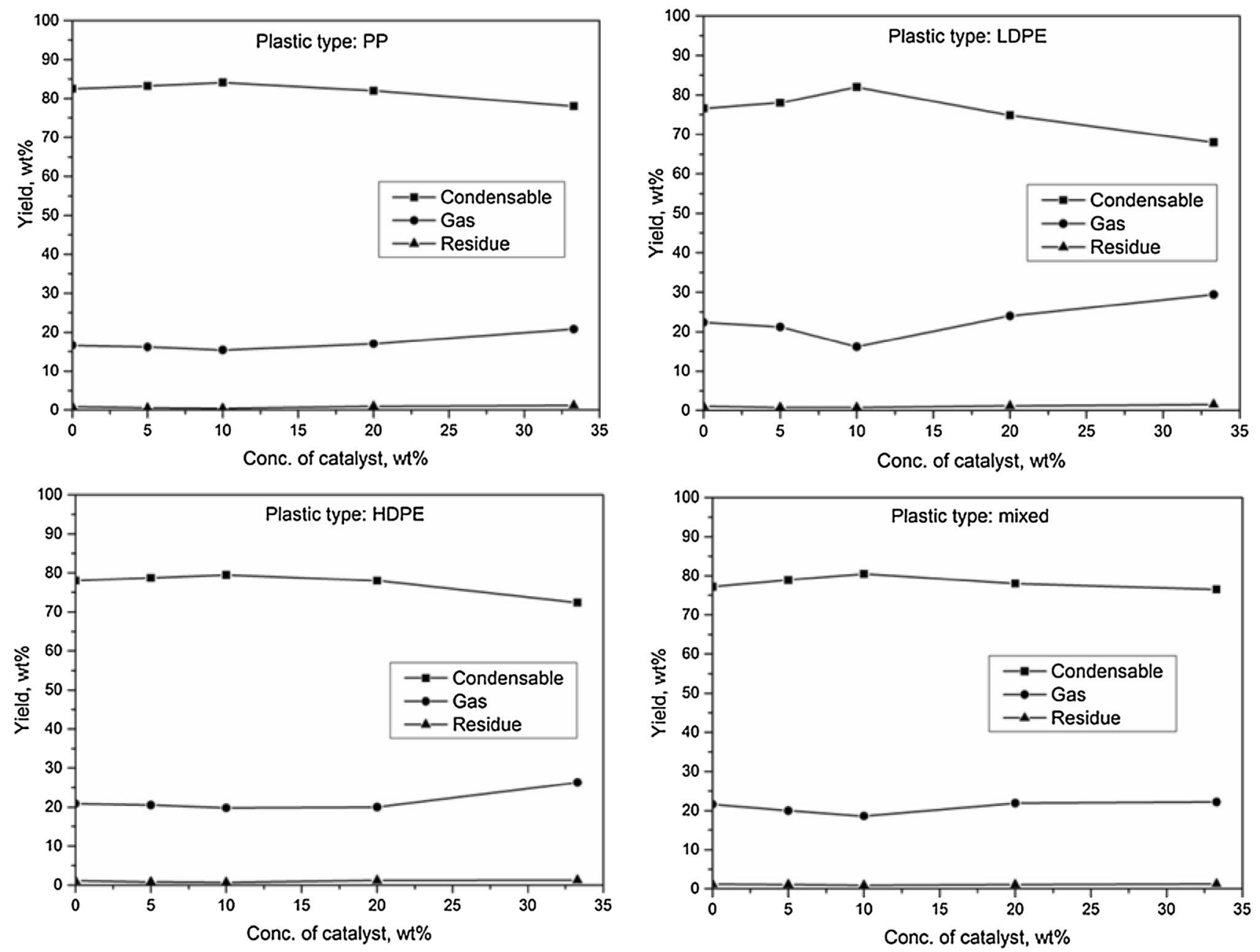

Fig. 6 Effect of catalyst concentration on the product distribution for different plastics. Temperature $=500{ }^{\circ} \mathrm{C}$

Table 1 Effect of catalyst concentration on the specific gravity of the oil at $500{ }^{\circ} \mathrm{C}$

\begin{tabular}{|c|c|c|c|c|}
\hline Catalyst concentration $\rightarrow$ & $5 \%$ & $10 \%$ & $20 \%$ & $33.3 \%$ \\
\hline Type of plastics $\downarrow$ & \multicolumn{4}{|c|}{ Specific gravity $(\mathrm{g} / \mathrm{ml}) @ 15^{\circ} \mathrm{C} / 15^{\circ} \mathrm{C} \downarrow$} \\
\hline Polypropylene & 0.797 & 0.767 & 0.730 & 0.701 \\
\hline Low density polyethylene & 0.842 & 0.815 & 0.799 & 0.789 \\
\hline High density polyethylene & 0.867 & 0.843 & 0.812 & 0.792 \\
\hline $\begin{array}{l}\text { Mixed plastics } \\
\text { PP + LDPE + HDPE } \\
(1: 1: 1)\end{array}$ & 0.832 & 0.810 & 0.779 & 0.762 \\
\hline
\end{tabular}

maximum oil yield was $10 \%$ at $500{ }^{\circ} \mathrm{C}$. The maximum yield of oil at the optimum condition of temperature and catalyst concentration was $84.1 \mathrm{wt} \%$ from PP, $82 \mathrm{wt} \%$ from LDPE, $79.5 \mathrm{wt} \%$ from HDPE and $80.5 \mathrm{wt} \%$ from mixed plastics. More catalyst (above 10\%) facilitates the secondary cracking to lighter fractions, thus yielding more gaseous products and thus less condensable fraction. This is also supported by the fact that increase of catalyst concentration decreased the specific gravity of the oil due to the formation of lighter fraction (Table 1).

\section{Chemical Composition of the Oil from Plastics}

The chemical composition of the plastic oil was obtained by FTIR and GC-MS techniques. The functional group composition of the different oils obtained from catalytic pyrolysis of HDPE, LDPE, PP and mixed plastics using 10\% catalyst at $500{ }^{\circ} \mathrm{C}$ are almost similar and contains aliphatic alkanes and olefins (see Fig. 7 for the FTIR of the oil samples obtained at the optimum condition of catalytic pyrolysis of different plastics). The oil obtained from all the plastic types carry similar assignments including $2857 \mathrm{~cm}^{-1}, 2870 \mathrm{~cm}^{-1}$, $2930 \mathrm{~cm}^{-1}, 2956 \mathrm{~cm}^{-1}$ corresponds to $\mathrm{C}-\mathrm{H}_{\text {stretching, }}$, $1452 \mathrm{~cm}^{-1}, 1494 \mathrm{~cm}^{-1}, 1456 \mathrm{~cm}^{-1}, 1651 \mathrm{~cm}^{-1}$ corresponds to $\mathrm{C}=\mathrm{C}_{\text {stretching }}$ and $1377 \mathrm{~cm}^{-1}, 970 \mathrm{~cm}^{-1}, 887 \mathrm{~cm}^{-1}$ corre-

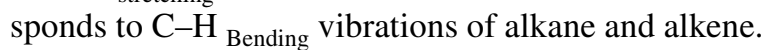




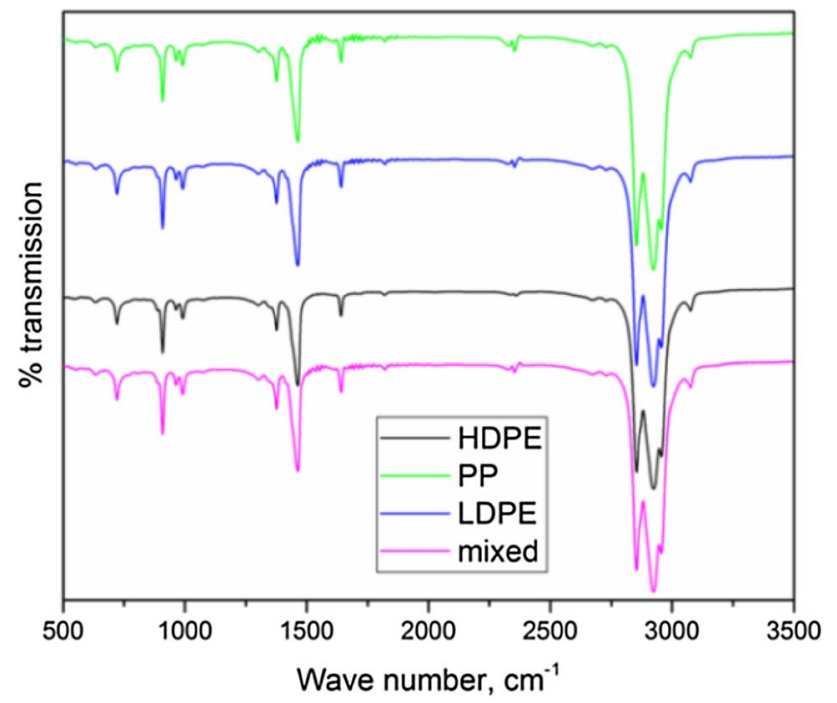

Fig. 7 FTIR of the oil samples obtained by the pyrolysis of different plastics at $500{ }^{\circ} \mathrm{C}$ and catalyst concentration of $10 \%$

The result of FTIR is supported by the GC-MS composition of the oil obtained from mixed plastics at optimum condition (Figure S1, supporting information, Table 2). The oil consists of 40 different components of alkane and olefins with carbon chain $\mathrm{C}_{10}-\mathrm{C}_{24}$. The result of the GC-MS studies is also supported by the literature. The $\mathrm{C}-\mathrm{C}$ bond is the weakest as compared to $\mathrm{C}-\mathrm{H}$ bond in the polymer structure. During the degradation process the stabilisation of the resultant radicals, after chain scission, leads to the formation of carbon double bonds $(\mathrm{C}=\mathrm{C})$ in the structure in addition to production of alkanes [22]. Consequently, a large number of compounds with carbon double bonds (alkenes) in the resultant oil would be expected. The thermal degradation of polypropylene has also been assigned to a random scission reaction which leads to the formation of a large number of hydrocarbon species. Polypropylene is similar in structure to polyethylene and thermal degradation via random scission would also result in the production of alkenes as well as alkanes [23]. The catalytic degradation of such polymers is known to proceed by carbenium ion mechanism. The initial step of the degradation reaction is considered to occur by either the abstraction of the hydride ion (by Lewis acid sites) from the polymer molecule or the addition of a proton (by Brønsted acid sites) to the $\mathrm{C}-\mathrm{C}$ bonds of the polymer molecule or thermally degraded olefins. The catalyst sulphated zirconium hydroxide contains both Lewis and Brønsted acid sites, as described previously, which helps the above steps. Successive scission of the main chain occurs to produce fragments having lower molecular weights. In addition, the product distribution was also changed in presence of the catalyst. The number
Table 2 GC-MS composition of the oil from mixed plastics at optimum condition

\begin{tabular}{|c|c|c|c|c|}
\hline Peak No & $\begin{array}{l}\text { Retention } \\
\text { Time } \\
(\min )\end{array}$ & $\begin{array}{l}\text { Area of } \\
\text { GC } \\
\text { peak }\end{array}$ & Compound & Formula \\
\hline \multicolumn{5}{|l|}{ Paraffins } \\
\hline 3 & 5.092 & 1.25 & Decane & $\mathrm{C}_{10} \mathrm{H}_{24}$ \\
\hline 8 & 6.875 & 1.58 & Undecane & $\mathrm{C}_{11} \mathrm{H}_{24}$ \\
\hline 11 & 8.524 & 1.44 & Dodecane & $\mathrm{C}_{12} \mathrm{H}_{26}$ \\
\hline 14 & 10.040 & 2.56 & Tridecane & $\mathrm{C}_{13} \mathrm{H}_{28}$ \\
\hline 16 & 11.429 & 2.42 & Tetradecane & $\mathrm{C}_{14} \mathrm{H}_{30}$ \\
\hline 19 & 12.729 & 2.95 & Pentadecane & $\mathrm{C}_{15} \mathrm{H}_{32}$ \\
\hline 23 & 13.940 & 3.04 & Hexadecane & $\mathrm{C}_{16} \mathrm{H}_{34}$ \\
\hline 26 & 15.091 & 2.97 & Heptadecane & $\mathrm{C}_{17} \mathrm{H}_{36}$ \\
\hline 28 & 16.183 & 2.64 & Octadecane & $\mathrm{C}_{18} \mathrm{H}_{38}$ \\
\hline 30 & 17.223 & 2.54 & Heptadecane & $\mathrm{C}_{17} \mathrm{H}_{36}$ \\
\hline 31 & 18.211 & 4.66 & Heptadecane & $\mathrm{C}_{17} \mathrm{H}_{36}$ \\
\hline 32 & 19.154 & 5.02 & Octadecane & $\mathrm{C}_{18} \mathrm{H}_{38}$ \\
\hline 33 & 20.061 & 4.76 & Nonadecane & $\mathrm{C}_{19} \mathrm{H}_{40}$ \\
\hline 34 & 20.930 & 4.28 & Nonadecane & $\mathrm{C}_{19} \mathrm{H}_{40}$ \\
\hline 35 & 21.762 & 4.61 & Heneicosane & $\mathrm{C}_{21} \mathrm{H}_{44}$ \\
\hline 36 & 22.564 & 3.09 & Tetracosane & $\mathrm{C}_{24} \mathrm{H}_{50}$ \\
\hline 37 & 23.337 & 3.60 & Heneicosane & $\mathrm{C}_{21} \mathrm{H}_{44}$ \\
\hline 38 & 24.080 & 2.57 & Tetracosane & $\mathrm{C}_{24} \mathrm{H}_{50}$ \\
\hline 39 & 25.491 & 2.07 & Tetracosane & $\mathrm{C}_{24} \mathrm{H}_{50}$ \\
\hline \multirow[t]{2}{*}{40} & 26.895 & 1.29 & Tetracosane & $\mathrm{C}_{24} \mathrm{H}_{50}$ \\
\hline & & 59.34 & & \\
\hline \multicolumn{5}{|l|}{ Olefins } \\
\hline 1 & 4.936 & 1.94 & cis-3-Decene & $\mathrm{C}_{10} \mathrm{H}_{20}$ \\
\hline 2 & 5.033 & 1.13 & 5-Decene & $\mathrm{C}_{10} \mathrm{H}_{20}$ \\
\hline 4 & 5.189 & 1.03 & cis-4-Decene & $\mathrm{C}_{10} \mathrm{H}_{20}$ \\
\hline 5 & 6.147 & 1.17 & $\begin{array}{l}\text { 4-Decene, 3-methyl- } \\
\text { (E)- }\end{array}$ & $\mathrm{C}_{11} \mathrm{H}_{22}$ \\
\hline 6 & 6.726 & 2.31 & 3-Undecene (Z)- & $\mathrm{C}_{11} \mathrm{H}_{22}$ \\
\hline 7 & 6.808 & 0.94 & 4-Dodecene & $\mathrm{C}_{12} \mathrm{H}_{24}$ \\
\hline 9 & 6.949 & 2.72 & 4-Undecene (E)- & $\mathrm{C}_{11} \mathrm{H}_{22}$ \\
\hline 10 & 8.390 & 2.83 & 5-Dodecene (E)- & $\mathrm{C}_{12} \mathrm{H}_{24}$ \\
\hline 12 & 9.809 & 2.47 & 6-Tridecene & $\mathrm{C}_{13} \mathrm{H}_{26}$ \\
\hline 13 & 9.921 & 3.08 & 5-Tetradecene (E)- & $\mathrm{C}_{14} \mathrm{H}_{28}$ \\
\hline 15 & 11.325 & 3.35 & 7-Hexadecene (Z)- & $\mathrm{C}_{16} \mathrm{H}_{32}$ \\
\hline 17 & 12.550 & 2.02 & 3-Heptadecene (Z)- & $\mathrm{C}_{17} \mathrm{H}_{34}$ \\
\hline 18 & 12.625 & 2.49 & 1-Pentadecene & $\mathrm{C}_{15} \mathrm{H}_{30}$ \\
\hline 20 & 12.914 & 0.77 & 1-Heptadecene & $\mathrm{C}_{17} \mathrm{H}_{34}$ \\
\hline 21 & 13.769 & 1.36 & 3-Octadecene (E)- & $\mathrm{C}_{18} \mathrm{H}_{36}$ \\
\hline 22 & 13.858 & 2.09 & 7-Hexadecene (Z)- & $\mathrm{C}_{16} \mathrm{H}_{32}$ \\
\hline 24 & 14.928 & 1.48 & 3-Heptadecene (Z)- & $\mathrm{C}_{17} \mathrm{H}_{34}$ \\
\hline 25 & 15.009 & 2.00 & 1-Heptadecene & $\mathrm{C}_{17} \mathrm{H}_{34}$ \\
\hline 27 & 16.109 & 3.06 & 1-Octadecene & $\mathrm{C}_{18} \mathrm{H}_{36}$ \\
\hline 29 & 17.149 & 2.42 & 1-Nonadecene & $\mathrm{C}_{19} \mathrm{H}_{38}$ \\
\hline Total & & 40.66 & & \\
\hline
\end{tabular}

of components in the thermal pyrolysis of PP and PE was 56 and $38[24,15]$ respectively whereas the sulphated 
Table 3 Fuel properties of the oil obtained from plastics

\begin{tabular}{|c|c|c|c|c|c|c|c|}
\hline \multirow[t]{2}{*}{ Parameters/test protocol } & \multicolumn{3}{|l|}{ Petro fuel } & \multicolumn{4}{|c|}{$\begin{array}{l}\text { Oil from catalytic pyrolysis at optimum tempera- } \\
\text { ture and catalyst concentration }\end{array}$} \\
\hline & Gasoline & Kerosene & Diesel & PP oil & LDPE oil & HDPE oil & Mixed plastics \\
\hline Colour & Yellow & Faint yellow & Orange & \multicolumn{4}{|c|}{ Straw yellow } \\
\hline Specific gravity $(\mathrm{g} / \mathrm{ml})$ at $15^{\circ} \mathrm{C} / 15^{\circ} \mathrm{C}$ I.S.1448: P.16 & $0.72-0.73$ & $0.78-0.82$ & $0.83-0.85$ & 0.767 & 0.815 & 0.843 & 0.810 \\
\hline Kinematic viscosity in cSt at $30^{\circ} \mathrm{C}$ I.S.1448: P:25 & $1.076-1.140$ & $1.54-2.2$ & $2.4-5.3$ & 2.24 & 2.31 & 2.38 & 2.29 \\
\hline Pour point I.S.1448: P:10 & - & - & - & \multicolumn{4}{|c|}{$<-40^{\circ} \mathrm{C}$} \\
\hline Cloud point I.S.1448: P:10 & - & - & - & \multicolumn{4}{|c|}{$<-40^{\circ} \mathrm{C}$} \\
\hline Gross calorific value (kcal/kg) I.S. 1448: P:6 & 11,201 & 10,867 & 10,162 & 46.32 & 42.15 & 43.11 & 46.78 \\
\hline Flash point by Abel $\left({ }^{\circ} \mathrm{C}\right)$ I.S.1448: P:20 & -42 & $50-55$ & $55-60$ & -22 & & & \\
\hline Fire point $\left({ }^{\circ} \mathrm{C}\right)$ I.S.1448: P:20 & -37 & 60 & 68 & -18 & & & \\
\hline Boiling point range $\left({ }^{\circ} \mathrm{C}\right)$ I.S. 1448:P.18 & $40-205$ & $175-325$ & $150-350$ & $65-340$ & $75-345$ & $70-345$ & $65-345$ \\
\hline
\end{tabular}

zirconium hydroxide catalysed pyrolysis of mixed plastics resulted in oil containing only 40 components with $59 \%$ alkane and $41 \%$ alkene. This indicates that the catalyst narrowed the product distribution.

\section{Properties of Oil}

The fuel properties of the oil obtained from different plastics at optimum conditions of temperature and catalyst concentration are summarized in Table 3 and are compared to different petro fuels. Figure S2 shows the images of plasticderived oils. The specific gravity of the oil is within the petro fuel (gasoline, kerosene and diesel) range. The viscosity of the plastic oils is higher than gasoline but within kerosene and diesel range. Pour point of the oil is very low and thus could be used without any problem during winter. The flash point and fire point of the oils also resembles with that of gasoline. The calorific values of the oils are also high enough and on a par with the petro fuels. The distillation range of the plastic oils is very large and thus can be separated into different fractions corresponding to gasoline, kerosene and diesel.

\section{Conclusions}

A thermo-catalytic pyrolysis process was designed using sulphated zirconium hydroxide as catalyst in a batch reactor for conversion of different plastics to liquid fuel. The maximum yield of oil for all the plastics was obtained at $500{ }^{\circ} \mathrm{C}$ using $10 \%$ catalyst. The oil yield was more than $79 \%$ for different plastics and contained $\mathrm{C}_{10}-\mathrm{C}_{24}$ hydrocarbons. The specific gravity of the oil is within the petro fuel (gasoline, kerosene and diesel) range. The viscosity of the plastic oil is within kerosene and diesel range. Pour point of the oil is low enough to be used in the cold weather. The calorific values of the oils are at par with the petro fuels. In summary, the fuel properties are suitable to be used as a substitute of fossil fuel.

Open Access This article is distributed under the terms of the Creative Commons Attribution 4.0 International License (http://creativeco mmons.org/licenses/by/4.0/), which permits unrestricted use, distribution, and reproduction in any medium, provided you give appropriate credit to the original author(s) and the source, provide a link to the Creative Commons license, and indicate if changes were made.

\section{References}

1. Geyer, R., Jambeck, J.R., Law, K.L.: Production, use, and fate of all plastics ever made. Sci Adv. 3(7), e1700782 (2017)

2. Wong, S.L., Abdullah, T.A.T., Ngadi, N., Ahmad, A., Inuwa, I.M.: Parametric study on catalytic cracking of LDPE to liquid fuel over ZSM-5 zeolite. Energy Convers Manag. 122, 428-438 (2016)

3. https://www.bpf.co.uk/article/the-plastics-industry-in-india-anoverview-446.aspx

4. Li, K.X., Lee, S.W., Yuan, G.A., Lei, J.X., Lin, S.X., Weerachanchai, P., Yang, Y., Wang, J.-Y.: Investigation into the catalytic activity of microporous and mesoporous catalysts in the pyrolysis of waste polyethylene and polypropylene mixture. Energies. 9(6), 431 (2016)

5. Panda, A.K., Singh, R.K., Mishra, D.K.: Thermolysis of waste plastics to liquid fuel: a suitable method for plastic waste management and manufacture of value added products - a world prospective. Renew Sust Energ Rev. 14(1), 233-248 (2010)

6. Keane, M.A.: Catalytic transformation of waste polymers to fuel oil. Chemsuschem 2(3), 207-214 (2009)

7. Butler, E., Devlin, G., McDonnell, K.: Waste polyolefins to liquid fuels via pyrolysis: review of commercial state-of-the-art and recent laboratory research. Waste Biomass Valor. 2, 227-255 (2011)

8. Kunwar, B., Cheng, H.N., Chandrashekaran, S.R., Sharma, B.K.: Plastics to fuel: a review. Renew Sust Energy Rev. 54, 421-428 (2016)

9. Aguado, J., Serrano, D.P., Escola, J.M.: Fuels from waste plastics by thermal and catalytic processes: a review. Ind Eng Chem Res. 47(21), 7982-7992 (2008) 
10. Burange, A.S., Gawande, M.B., Lam, F.L.Y., Jayaram, R.V., Luque, R.: Heterogeneously catalyzed strategies for the deconstruction of high density polyethylene: plastic waste valorisation to fuels. Green Chem. 17(1), 146-156 (2015)

11. Serrano, D.P., Aguado, J., Escola, J.M.: Developing advanced catalysts for the conversion of polyolefinic waste plastics into fuels and chemicals. ACS Catal. 2(9), 1924-1941 (2012)

12. Akubo, K., Nahil, M.A., Williams, P.T.: Aromatic fuel oils produced from the pyrolysis-catalysis of polyethylene plastic with metal-impregnated zeolite catalysts. J Energy Inst. 9, 195-202 (2019)

13. Till, Z., Varga, T., Soja, J., Miskolczi, N., Chovan, T.: Kinetic identification of plastic waste pyrolysis on zeolite-based catalysts. Energy Convers. Manag. 173, 320-330 (2018)

14. Sebestyen, Z., Barta-Rajnai, E., Bozi, J., Blazso, M., Jakab, E., Miskolczi, N., Soja, J., Czegeny, Z.: Thermo-catalytic pyrolysis of biomass and plastic mixtures using HZSM-5. Appl Energy 207, 114-122 (2017)

15. Kumar, S., Singh, R.K.: Recovery of hydrocarbon liquid from waste high density polyethylene by thermal pyrolysis. Braz J Chem Eng. 28(4), 659-667 (2011)

16. Morterra, C., Cerrato, G., Pinna, F., Signoretto, M.: Crystal phase, spectral features, and catalytic activity of sulfate-doped zirconia systems. J Catal. 157, 109-123 (1995)

17. Shiju, N.R., Yoshida, K., Boyes, E.D., Brown, R., Gai, P.L.: Dynamic atomic scale in situ electron microscopy in the development of an efficient heterogeneous catalytic process for pharmaceutical NSAIDS. Catal Sci Technol. 1, 413-425 (2011)
18. Filiz, B.C., Gnanakumar, E.S., Martínez-Arias, A., Gengler, R., Rudolf, P., Rothenberg, G., Shiju, N.R.: Highly selective hydrogenation of levulinic acid to $\gamma$-Valerolactone over $\mathrm{Ru} / \mathrm{ZrO}_{2}$ catalysts. Catal Lett. 147, 1744-1753 (2017)

19. Bandyopadhyay, M., Shiju, N.R., Brown, D.R.: MCM-48 as a support for sulfonic acid catalysts. Catal Commun. 11(7), 660-664 (2010)

20. Nair, G.S., Adrijanto, E., Alsalme, A., Kozhevnikov, I.V., Cooke, D.J., Brown, D.R., Shiju, N.R.: Glycerol utilization: solvent-free acetalisation over niobia catalysts. Catal Sci Technol. 2(6), 11731179 (2012)

21. Panda, A.K.: Thermo-catalytic degradation of different plastics to drop in liquid fuel using calcium bentonite catalyst. Int J Ind Chem. 9, 167 (2018)

22. Pacakova, V., Leclercq, P.A.: Gas chromatography-mass spectrometry and high-performance liquid chromatographic analyses of thermal degradation products of common plastics. J Chromatog. 555, 229-237 (1991)

23. Turi, E.A.: Thermal characterization of polymeric materials. Academic, New York (1981)

24. Panda, A.K., Singh, R.K.: Conversion of waste polypropylene to liquid fuel using acid-activated kaolin. Waste Manag Res. 32(10), 997-1004 (2014)

Publisher's Note Springer Nature remains neutral with regard to jurisdictional claims in published maps and institutional affiliations. 